\title{
Participating mortgages and the efficiency of financial intermediation $^{\text {th }}$
}

\author{
M. Shahid Ebrahim ${ }^{\mathrm{a}}$, Mark B. Shackleton ${ }^{\mathrm{b}}$, Rafał M. Wojakowski ${ }^{\mathrm{b}, *}$ \\ ${ }^{a}$ Bangor Business School, Bangor, UK \\ ${ }^{b}$ Lancaster University Management School, Lancaster, UK
}

\begin{abstract}
This paper establishes a basic framework to study three different variants of Participating Mortgages (PMs). We obtain results for Shared Appreciation (SAMs), Shared Income (SIMs) and shared Equity Mortgages (SEMs) in closed-form. We illustrate our findings with examples that show PMs are also attractive in an environment where prepayment can occur. Finally we conclude with the public policy implications of employing PMs as workout loans, especially post sub-prime crisis. We argue that by facilitating better risk sharing, PMs offer a means to enhance the efficiency and resiliency of the financial system.
\end{abstract}

JEL classification: C63; D11; D14; D92; G13; G21; R31

Keywords: Participating mortgage; Shared appreciation mortgage; Shared income mortgage; Shared equity mortgage; Profit caps and floors; Prepayment risk intensity

\footnotetext{
${ }^{\sqrt{3}}$ We are grateful for helpful comments and suggestions to Mark Beardsell, Peter Carr, Amy Crews Cutts, Bernard Dumas, Piet Eichholtz, Michael Gallmeyer, David Geltner, Massimo Guidolin, Douglas McManus, Ser-Huang Poon, Robert Seymour, Dogan Tirtiroglu and Łukasz Wojakowski

${ }^{*}$ Corresponding author. Tel.: +44(1524)593630; fax: +44(1524)847321.

Email addresses: m.s.ebrahim@bangor .ac.uk (M. Shahid Ebrahim), m.shackleton@lancaster.ac.uk (Mark B. Shackleton), r.wojakowski@lancaster.ac.uk (Rafał M. Wojakowski)

URL: http://www. lancaster.ac.uk/staff/wojakows/ (Rafał M. Wojakowski)
} 


\section{Introduction}

It is paramount that a financial intermediation system operates efficiently (see Blejer (2006)). Since financial intermediaries connect real estate prices with the macroeconomy, Glaeser (2007) reinforces this issue by arguing that inefficient intermediation increases risk in the economy. The purpose of this paper is to study an extremely versatile family of lending facilities, which make the financial intermediation system more resilient to economic shocks, more efficient and thus more liable to foster economic growth. The specific questions we study in this paper are as follows: How can mortgages be designed so as to absorb house price shocks and lessen macroeconomic shocks? How can we structure these financial products so that they are versatile and of benefiting to borrowers? How do we establish a general pricing framework where generic versions and their variants separate speculation from defaultable lending?

Following the sub-prime crisis, the use of inflexible plain vanilla mortgages in the US has caused intense pressure within the global financial system and shown the current lending system to be inefficient, in the sense that risks have needlessly propagated. This crisis was triggered by homeowners who inadvertently transferred risk when reacting to one of several motivations. They extracted a substantial amount of equity from their homes through refinancing (see Khandani et al. (2009); LaCour-Little et al. (2009); and Mian and Sufi (2009)) or took on an extraordinary amounts of debt in order to increase consumption compared to their permanent income (see Hurst and Stafford (2004); Chomsisengphet and Pennington-Cross (2006); and Doms and Krainer (2007)) $!^{1}$

Qi and Yang (2009) attribute foreclosure risks to the high loan to value (LTV) ratio of mortgages, so as this ratio increased, risk was transferred to the lenders. This is because a high LTV exacerbates moral hazard (due to lack of investor capital at risk - also termed "no skin in the game") and adverse selection due to difficulties in screening borrowers with potential high-income

\footnotetext{
${ }^{1}$ In general, alternative mortgages such as adjustable rate mortgages (ARMs) are not appropriate for households with a large mortgage, volatile income, high default cost or low moving probability (see Campbell and Cocco (2003) and Campbell (2006)).
} 
growth. Thus a first time homeowner is vulnerable to foreclosures because of the high initial LTV (where the equity cushion is the lowest) and larger regular debt payments to service the mortgage relative to income. This is specially so at the end of an introductory teaser rate (see Lekkas et al. (1993)). The risk-shifting theory is also elaborated by Daglish (2009) by examining the default put option embedded in all mortgages.

Risk shifting on refinancing constitutes a systemic risk faced by financial institutions as it leads to termination of loans at inopportune periods of low interest rates. Krainer and Marquis (2004) shed light on this by modelling the mortgage in a continuous time setting to evaluate the impact of house price increases and interest rate cuts on aggregate consumption. They demonstrate that the amount of refinancing is contingent not only on recent interest rate changes (or levels) but also on the history of these variables as well as that of house prices. The financial services industry prices the refinancing risk in a fixed rate mortgage (FRM) either through a separate origination fee (which includes an up-front outlay to a mortgage broker, termed as points) or an increment to the interest rate of the underlying facility. Through the years, the industry has come to offer a complex menu of fixed rate mortgages to segregate potentially mobile borrowers (who would pay off or refinance) from potentially immobile ones (see Stanton and Wallace (1998)).

By resorting to intermediate instruments designed to reduce the fragility of the financial system, there have been various attempts to revive the economy and its growth prospects by improving its stability and resilience to housing shocks, in accordance with Blejer (2006). One such solution, explored in this paper, is the use of Participating Mortgages (PMs). At the expense of sharing their upside payoffs (appreciation and/or income) with the financier, these mortgages allow borrowers to remain owners of their property at times of crisis by lowering their interest rate. As a result, PMs make refinancing at lower rates more attractive for lenders as well as borrowers.

In contrast to PMs, use of plain vanilla debt (or mortgage) is inefficient since these instruments lie on the lowest rung of Pareto-efficiency (see Ebrahim and Hussain (2010)). The fundamental issue with plain vanilla debt is that by construction the rigid payments confers fragility to the finan- 
cial intermediation system, irrespective of whether they ensue from Fixed Rate (FRM), Adjustable Rate Mortgages (ARM) or a hybrid of the two (see Stiglitz (1988); Reinhart and Rogoff (2008a) and (2008b)). Modigliani (1974) reiterates this quite strongly when he states that:

As long as loan contracts are expressed in conventional nominal terms, a high and variable rate of inflation - or more precisely a significant degree of uncertainty about the future price level—can play havoc with financial markets and interfere seriously with the efficient allocation of the flow of savings and the stock of capital.

This paper studies a range of Participating Mortgages, also known as Participating Loans, which enhance the financial architecture and make it more resilient to systemic risk by allowing intermediation to absorb shocks in the system rather than transmit them all. These facilities are extremely versatile and lie on the highest rung of Pareto-efficiency (see Ebrahim and Hussain (2010)). In the real estate sector, investors are subject to a two-sided risk in the forms of business risks (stemming from soft real estate markets due to poor economic conditions or oversupply leading to low rents and appreciation) and financial risks (stemming from the fixed obligations of a loan). A PM in general and a Shared-Appreciation Mortgage (SAM) in particular partially immunize these risks as they trade the fixed obligations of debt off against potential capital appreciation without transferring the downside risk of the investment to the financiers. A PM avoids the underinvestment issue highlighted in Myers $(1977)$ where the wealth enhancement associated with real estate investment accrues primarily to financiers. Thus, from the perspective of a financier, a $\mathrm{PM}$ is preferable as it mitigates the agency costs of debt by restraining both risk-shifting and underinvestment. Due to the equity like nature of these facilities PMs (as elaborated below) are able to reduce the vulnerability of the financial system to default since their obligatory payments are neither completely fixed nor floating with interest rates (as in the case of plain vanilla mortgages). This is because payments can depend upon the underlying asset itself. PMs substitute rigid interest payments with uncertain (stochastic) payments contingent on appreciation and/or income from a 
property. They therefore enhance the efficiency of the financial intermediation system in the sense of Blejer (2006).

Within a single platform the prime contribution of this paper is to introduce extra dimensions into the financing framework allowing PMs to improve the efficiency of the financial system. To this end we present a model within which speculation and defaultable lending are separated by construction 2 We price several variants in closed-form (using profit caps) and discuss their employment as workout loans in the ongoing sub-prime crisis. We rely on valuation methodology applicable to continuous flows (see e.g. Carr, Lipton and Madan (2000) and Shackleton \& Wojakowski (2007)). Pricing a PM in closed-form allows calibrate of the model and derivation of precise solutions. These solutions can serve as common ground for market participants when discussing important parameters such as implied real estate volatility. Examination of the closed form solutions also leads to a better understanding of practitioner issues.

We implicitly assume the existence of an information architecture espoused in Levine et al. (2000). That is, an economy where property rights, foreclosure procedures (needed for real estate to serve as collateral) and accurate methods of valuing property are well established ${ }^{3}$ In this setting, we employ formulae derived in Shackleton and Wojakowski (2007) and we improve the efficiency of the financial system by parametrising the variants of a PM (using profit caps) and discuss their employment as workout loans in the ongoing sub-prime crisis.

\footnotetext{
${ }^{2}$ Using tradeable assets on property markets, lending and speculation can be separated and defaultable lending can occur without property risk. In fact, the key contribution of our paper is to offer a model within which speculation and lending are separated by construction. The analogy is one of a derivatives trader, who synthesizes options. Traders sell puts (or buy calls and discount the coupon, as in our case) even when the market is expected to fall because they can locally hedge away the risk. Thus the bank can make money on mispricing rather than speculation, i.e. acting like an arbitrageur whenever there is a difference between buying the PM for less than it's formulaic fair value (i.e. lending less than fair value). At the same time the lender can delta hedge in property futures in order to immunize the loan from the outcomes of up and down movements of property prices.

${ }^{3}$ This assumption facilitates underwriting mortgages in a complete market setting where contracts spanning each state of the economy are clearly and unambiguously written. That is, this assumption allows banks to easily mitigate real world problems as follows: (1) Adverse Selection is alleviated by releasing funds in the escrow process when the title of the specific property being purchased is exchanged for cash; (2) Moral Hazard is dissipated by mandating the following in the mortgage covenant: (i) minimum maintenance on the property; (ii) payment of taxes; and (iii) adequate insurance coverage. See Smith and Warner (1979) for more information on debt contracting using covenants.
} 
The paper is organized as follows. In the next section, we elaborate more on PMs and their variants constituting of Shared Income Mortgages (SIMs), Shared Equity Mortgages (SEMs) and Shared Appreciation Mortgages (SAMs). The following section discusses the theoretical underpinnings behind a standard mortgage followed by a PM and its variants such as SIM, SEM and SAM respectively. The next section explicates the prepayments of PMs and its variants. The final section concludes.

\section{Participating mortgages}

Participating Mortgages (PMs) are a family of facilities secured by real estate assets where the lender gets a proportion of payoffs either in the operating stage or repayment stage or both. The borrower trades off the participation feature of the loan with the lender by either having the loan's coupon rate set below the prevailing market interest rate and/or being granted a higher initial loan to value ratio. Depending on the contract, usually non-standardized and negotiated over the counter, the lender participates in either gross or net operating income, cash flows after senior debt service or proceeds from sale of the property.

PMs have traditionally been employed to reconcile diverging interests of financiers and investors, particularly in the area of construction loans. This is because it can take several years for a green field development to generate sufficient cash flow levels to comfortably service debt obligations. Investors who obtain financing are exposed to increased default risk during this construction phase, while lenders are normally excluded from sharing the upside potential of a project (in a traditional fixed-rate mortgage). By offering participation clauses, borrowers benefit from lower regular debt payments, especially in the gestation phase of a new development. Conversely, lenders benefit from expected future payoffs, typically in the operating and/or the maturity phase.

By allowing more investors to qualify, PMs are a financial innovation which facilitate ownership of real estate because a lower down payment alleviates moral hazard (as the mortgage embeds a call option to participate in the potential appreciation of the property) and permanently lower re- 
quired debt payments alleviate the asymmetry of information on the borrower's income growth (as she trades off the fixed cost of financing with that of a share in the income and/or the growth of the property).

Early studies focus on a special case of PMs, namely SAMs (elaborated further below). SAMs facilitate purchase of owner occupied homes by reducing the impact of the two constraints (discussed above) of down payment and regular debt payments that restrict access to funded homeownership. In contrast to a subprime mortgage, this is accomplished without subjecting the homeowner to high, fixed debt payments. This confers a SAM (and a PM) an advantage over a regular subprime mortgage, where the young and educated were able to consume high levels of housing in anticipation of future income growth (measured as permanent income in Hurst and Stafford (2004) and Doms and Krainer (2007)). In other words to reduce foreclosures and thus the vulnerability of the financial intermediation system to shocks (again see Ebrahim and Hussain (2010)) a SAM (and a PM) are able to restrain the risk-shifting behaviour of households. Thus, the probability of foreclosures under PMs could even decrease after a fall in property prices. Finally since the regular payments to borrowers are variable foreclosure is again not an issue if refinancing is not an option (in accordance with the recursive contract theory of mortgage financing developed in Krainer and Marquis (2004)).

Contributions to SAM's literature include (i) French and Haney (1984) (who use an option approach, thereby improving on Dougherty, Van Order and Villani (1982) who assume deterministic property prices), (ii) Page and Sanders (1986), who study the impact of house and interest rate risks on SAMs; (iii) Murphy (1990), who practically analyses SAMs, using simulation and (iv) Sanders and Slawson (2005), who assume stochastic house prices in conjunction with stochastic interest rates to numerically simulate SAM prices.

Despite these valuable attributes, the academic literature shedding light on the versatility and pricing of PMs is still limited (see Alvayay et al. (2005)). ${ }^{4}$

\footnotetext{
${ }^{4}$ We make a general statement with a notable exception of SAMs. In a sense, SAMs are easier to price and
} 
More importantly, most academic studies (and government policies) do not realize that PMs can be superior if employed as primary financing and workout vehicles. Ebrahim (1996) establishes Pareto-superiority of participating mortgages in an overlapping generations framework while Ebrahim and Hussain (2010) demonstrate that participating securities exemplify the developed stage of a financial system.

Using a PM (or any of its variants in the form of SIM, SEM or SAM), the following four features of distinguish features of borrowers exist compared to those opting for alternative mortgages (in the sense of Stanton and Wallace (1998)). First, PMs are a financial innovation that facilitates real estate ownership by relaxing the down payment and income constraints. They therefore appeal to real estate investors who are subject to these binding constraints (in terms of LTV, and income ratio). Second, since this class of instrument involves quasi-equity, they appeal to long-term individual investors (and not asset flippers) who would like to match the cost of financing with their income along with the growth in value of the asset, instead of just their permanent income in case of alternative mortgages (see Hurst and Stafford (2004) and Doms and Krainer (2007)). To extract reasonable amount of equity and deter asset flippers, lenders otherwise need to impose a sliding penalty over the prepayment period (with the exception of refinancing with the same vendor and with the same type of PM). Third in addition to the credit risk of the borrower, this class of instrument prices the contract based on the type, quality and location of individual property. Consequently, contract terms discriminate between borrowers based on these attributes. Fourth, a PM avoids risk-shifting by restraining investors from extracting unreasonable amounts of equity on refinancing, leading to their use by conservative rather than aggressive borrowers.

The depressed real estate sector of the current economy offers an excellent opportunity for the implementation of PMs - which is particularly straightforward in the case of SAMs-to reduce the hardship of subprime borrowers whose teaser rate has expired (see Glaeser (2007) and Summers

implement as they only require one future observation, i.e. house value at loan maturity or when sold. In contrast, PMs require incorporation of intermediate values of income, observed at regular points in time during the life of the contract. 
(2008)). This requires modification of the mortgage in a way to alleviate the hardship of borrowers by offering permanently low interest payments (instead of the introductory teaser rates in the subprime mortgage case) and allow the financial institution to recoup interest by participating in the appreciation of the property and/or in future income.

The participating features of mortgages mitigate agency costs thereby enhancing the value of the underlying property. This perspective is also supported by the practitioner literature, which highlights the affordability of higher value property with PM financed loans (see Caplin et al. (2007)).

INSERT Figure 1 ABOUT HERE.

Different variations of participating mortgages are defined by Ebrahim and Hussain (2010). These include the following forms observed in practice:

1. Shared Appreciation Mortgage (SAM), where the investor (owner occupied homeowner) trades off the debt obligations against the potential appreciation of the property.

2. Shared Income Mortgage (SIM), where the investor trades off the debt (i.e., interest) obligations against a part of the income of the real estate venture:5

3. Shared Equity Mortgage (SEM), where the investor trades off the debt itself (and the debt obligations) against both the income and potential appreciation of the property;

These different contracts are represented in Figure 1 as a function of three factors and associated variables:

1. Time Value of money, represented by interest rate $i$;

2. Capital Appreciation, represented by value of property $H$;

3. Income, represented by profit flow $P$.

\footnotetext{
${ }^{5}$ One cannot contract on a fraction of household or labour income above a preset threshold to satisfy the requirement of an SIM due to asymmetric information on its growth and associated moral hazard.
} 
In the case of a SAM, a positive appreciation fraction $\theta_{H}>0$ is traded-off against the required interest rate $i$. Typically, this type of contract does not involve participation in the rental income component. Consequently, the property income participation ratio is set to zero $\left(\theta_{P}=0\right)$.

In the case of a SIM, a positive income participation fraction $\theta_{P}>0$ of profit flow $P$ is tradedoff against interest rate $i$ required by the lender. Typically, this type of contract does not involve participation in capital appreciation. Consequently, the participation ratio related to appreciation of the property value is set to zero $\left(\theta_{H}=0\right)$.

In the case of a SEM, the financier shares both income and appreciation risks and is rewarded by a positive participation $\theta_{P}>0$ in income as well as by positive participation in capital appreciation $\theta_{H}>0$. In this type of contract it is possible to completely forego coupon payments, so that the required interest is set to zero $(i=0)$.

PMs and its variants in the form of SAMs, SIMs and SEMs can play a vital role in increasing the welfare of owners of real estate from both commercial as well as residential sectors. In contrast, only SAMs play a crucial role in enhancing the welfare of owner occupied homes. This is attributed to portfolio diversification thereby reducing the allocation of equity along with the periodic obligation of servicing the debt (see Dougherty et al. (1982)). See also Freiberg (1982), and Sanders and Slawson (2005) for more information.

Payoffs to original equity holders are diluted in the good states of the economy for both PMs and convertible mortgages. However, PMs are more appealing than convertible mortgages since: (i) a general PM is more versatile than a convertible facility since it offers a large number of possible variants, with SAM, SIM and SEM illustrating the three most frequently encountered special cases; (ii) an investor retains control of the underlying property over the tenure of the PM unlike in the case of a convertible security where conversion to equity in good states of the economy dilutes control rights as well as value (see Lee et al. (2009)). 


\section{The model}

Assuming the feasibility of hedging the underlying real estate assets, we describe the profit process as follows

$$
d P_{t}=(r-\delta) P_{t} d t+\sigma P_{t} d Z_{t},
$$

where $Z_{t}$ is the corresponding Brownian motion under the risk-neutral measure $Q, r$ is the risk-free interest rate and $\delta$ is a constant cash yield, which is analogous to the dividend rate in case of a stock. Depending on the context i.e. commercial or investment property, the cash flow $P$ can be interpreted as income from operations or renting. 6 A more intrepid interpretation in the case of a household includes salary income as source of cash flow $P$.

Throughout this paper we adopt the convention that $E[x]$ is the expectation taken at time $t=0$ under the equivalent martingale measure $Q$ i.e. $E[x]=E^{Q}\left[x \mid \mathcal{F}_{0}\right]$ and $E_{t}[x]=E^{Q}\left[x \mid \mathcal{F}_{t}\right]$, where $\mathcal{F}_{t}$ is information available at time $t$. In our context all mortgage contracts are of finite maturity, while the profit flow $P_{t}$ is assumed to be of infinite duration (i.e. $t \in[0, \infty)$ ). The property value $H_{t}$ is assumed to be driven by the process

$$
d H_{t}=\left(r-\delta_{H}\right) H_{t} d t+\sigma_{H} H_{t} d Z_{t}^{H},
$$

where $\delta_{H}$ can be explained as the rental rate. Such an interpretation of the cash yield parameter $\delta_{H}$ is in the context of housing finance (see Capozza et al. (1998)). A more general meaning of $\delta_{H}$ involves a service flow from using the property over time, as in Kau et al. (1992). The $\sigma_{H}$ is then the volatility of real estate, different from the dispersion parameter $\sigma$ of the profit cash flow process $P_{t}$. In (2), $Z_{t}^{H}$ represents the risk-neutral standard Brownian motion process driving real estate prices. For simplicity, we assume that the correlation of real estate price returns with the stochastic component $d Z_{t}$ driving profit cash flows is equal to $\rho=0$ so that the instantaneous risk-neutral value of $d Z_{t} d Z_{t}^{H}=\rho d t$ is also equal to zero.

\footnotetext{
${ }^{6}$ Investment property corresponds to buy-to-let in British terminology.
} 
We model housing prices by employing Brownian motion under a risk-neutral measure instead of Lévy processes, which incorporate an unaccountable number of jumps. Adding jumps makes sense in presence of risk of large price movements over very short time intervals, such as stock price movements which can be observed at high frequencies. In contrast, property prices and inputs for home price indices are not frequently observable and based on averages. Compared to stock price time series, home price series are very smooth. They are also "patchy," as they cannot be observed very frequently. Based on these two characteristics, it seems that when making continuous-time approximations (as is the case of our model) the most important thing to take into account is to make sure that volatility is low and thus home prices are smooth. Introducing jumps would be a worthwhile extension of our current setup that would allow for modelling of locally unpredictable information. However, using Lévy processes, though a very interesting and worthwhile extension of our setup for future research, would be beyond the scope of our present paper. A simpler way to add a few jumps to the property prices would be to start with a Poisson process as in Merton (1976) and add the extra terms to Equation (2). Instead, we prefer to focus on the use of this form of randomness on Poisson jumps governing our prepayment intensity in Section 4 believing it to be a more important issue.

\subsection{Participating mortgages versus standard mortgage loans}

\subsubsection{Standard mortgage loans}

Consider a conventional fixed-rate mortgage, known as a standard loan. At time $t=0$ the investor makes an initial deposit $D_{0}$ against property valued at $H_{0} .7$ The lender finances the net loan amount $Q_{0}$ and the time to maturity or tenure is $T$. The lender imposes a maximum permitted loan-to-value ratio $\bar{L}$ (typically $\bar{L}<1$, e.g. 90\%). That is, a minimum equity condition, such that

$$
Q_{0}=H_{0}-D_{0} \leq \bar{L} H_{0}
$$

\footnotetext{
${ }^{7} \mathrm{We}$ assume that there are special techniques to ascertain the market value of a property from the appraisal based data (see Geltner et al. (2003)). In particular, this implies that the market price of the property and its estimated value do not differ.
} 
implying that the initial deposit, $D_{0}$, must be greater than $\underline{D}$, where

$$
\underline{D}=H_{0}(1-\bar{L}) \leq D_{0}
$$

The coupon schedule $\left\{a_{t}: t \in[0, T]\right\}$ is an agreed clause in the loan. The value of the loan at time $t=0$ must be equal to the discounted expected value of future loan cash-flows, i.e., coupons and terminal balance

$$
Q_{0}=\int_{0}^{T} e^{-r t} E\left[a_{t}\right] d t+e^{-r T} E\left[Q_{T}\right]
$$

where $E$ is the risk-neutral expectation operator. This is a very general expression. It must be satisfied by intermediate cash flows and by the terminal cash flow. The borrower is required to pay the continuous interest coupon flow $a_{t}$ and reimburse the remaining principal $Q_{T}$ at maturity. Note that the infinitesimal coupon amount paid during time $d t$ is $a_{t} d t$, while the coupon flow rate (per unit of time) is $a_{t}$.

To begin, consider non amortizing loans. The outstanding balance remains constant, equal to the initial loan amount $Q_{0}$, so that $Q_{t}=Q_{0}$ for all $t$, implying $Q_{T}=Q_{0}$. In this case the agreed coupon structure is typically constant in time and can be fully characterized by a single parameter $i$. It is known as cost of funds and is equal to the lender's required, continuous coupon rate, such that

$$
a_{t}=i Q_{t}=i Q_{0}=a_{0}
$$

If the loan is riskless-there is no default or prepayment risk-cash flows bear no risk. This simplifies expression (5) and yields

$$
i=r \quad \Longrightarrow \quad a_{t}=r Q_{0} \text {. }
$$

\subsubsection{Participating mortgages}

A general Participating Mortgage (PM) includes some fixed interest payments similar to a standard mortgage loan, in addition to cash flows from either or both of: 
1. A proportion $\theta_{H}>0$ of the appreciation of the property value above its starting value $H_{0}$, for Shared Appreciation Mortgages (SAM);

2. A proportion $\theta_{P}>0$ of the excess income, above some threshold value $K>0$, for a Shared Income Mortgages (SIM).

The budget constraint for a general Participating Mortgage (PM) becomes

$$
\begin{aligned}
Q_{0} & =E\left[\int_{0}^{T} e^{-r t} i Q_{t} d t\right]+E\left[e^{-r T} Q_{T}\right] \\
& +E\left[e^{-r T} \theta_{H}\left(H_{T}-H_{0}\right)^{+}\right]+E\left[\int_{0}^{T} e^{-r t} \theta_{P}\left(P_{t}-K\right)^{+} d t\right],
\end{aligned}
$$

where $x^{+}$is the positive part function, equal to $x$ if $x>0$ and to zero otherwise. This condition tells us that the initial value of the loan (left hand side) must be equal to the expected present value of future payments (right hand side). Future payments are, respectively:

- intermediate interest payments $i Q_{t}$ at contract rate $i$ on principal outstanding $Q_{t}$;

- intermediate shared income payments $\theta_{P}\left(P_{t}-K\right)^{+}$contingent on the level of profit flow $P_{t}$ earned at time $t \in[0, T]$;

- terminal payment of principal $Q_{T}$ remaining at maturity $T$;

- terminal shared property appreciation payment $\theta_{H}\left(H_{T}-H_{0}\right)^{+}$made at maturity $T$.

All intermediate payments are made continuously for all times $t$ within the product's lifetime $[0, T]$. Terminal payments are made at maturity $T>0$.

Compared to standard mortgage loan (5) there are two additional terms here. First, the lender is compensated proportionally to the appreciation $\left(H_{T}-H_{0}\right)^{+}$, if positive, of the value of the property, where $H_{0}$ and $H_{T}$ are the initial and terminal values of the property. Second, the lender is compensated proportionally to the excess intermediate profit flow $\left(P_{t}-K\right)^{+}$where $K$ is the fixed profit threshold above which participation is payable. 
For non-amortizing loans the budget constraint (8) gives

$$
\bar{L} H_{0}\left(1-e^{-r T}\right)=\bar{L} H_{0} \frac{i}{r}\left(1-e^{-r T}\right)+\theta_{P} C\left(P_{0}, K, r, \delta, \sigma, T\right)+\theta_{H} c\left(H_{0}, H_{0}, r, \delta_{H}, \sigma_{H}, T\right)
$$

where $C$ is a profit cap (on $P_{t}$ ) and $c$ is a call option (on $H_{T}$ ). Both functions can be computed explicitly using the cap formula (39) with $\lambda=0$ (see section 4 below) and the Black-Scholes call formula 23 , respectively. Recall that $\bar{L}$ is the loan to value ratio, $H_{0}$ is the initial house value, $r$ is the risk-free rate, $i$ is the contract rate, $T$ is the time to maturity, $P_{0}$ is the initial value of the profit flow, $K$ is the profit flow threshold, $\delta$ and $\delta_{H}$ are the cash yield and the rental rate, while $\sigma$ and $\sigma_{H}$ are cash flow and house price volatilities.

Condition (97) tells us that the present value of the net interest on the loan (left hand side) is attributable to the fraction $i$ of annuity (first term), participation $\theta_{P}$ in the income and participation $\theta_{H}$ in the appreciation of property value. Because of these two additional sources of revenue to the lender, the required coupon rate $i$ can be reduced to accommodate lender's participation, so that $i<r$.

It is straightforward to express $i$ as a function of other parameters of the model to see that for positive participation ratios $\theta_{P}>0$ and $\theta_{H}>0$ the interest $i$ must be reduced below the prevailing market rate $r$

$$
\underbrace{i}_{\text {contract rate }}=\underbrace{r}_{\text {market rate }}-\underbrace{\frac{r C\left(P_{0}, K, r, \delta, \sigma, T\right)}{\bar{L} H_{0}\left(1-e^{-r T}\right)} \theta_{P}}_{\text {participation }}+\underbrace{\frac{r c\left(H_{0}, H_{0}, r, \delta_{H}, \sigma_{H}, T\right)}{\bar{L} H_{0}\left(1-e^{-r T}\right)} \theta_{H}}_{\text {income }}]<r .
$$

The above equation explains in detail the trade-off between interest rate $i$ and participating parameters $\theta_{P}$ and $\theta_{H}$. It also illustrates that the PM is more flexible than a convertible mortgage as one can opt for different combinations of $\theta_{P}$ and $\theta_{H}$ unlike the case of convertible where one is constrained to a fixed amount at the time of conversion. Here too, the above trade-off has the capacity to reduce high fixed debt payments and thus defaults. This helps to improve the flexibility of the 
financial system. 8

In general, participating loans are not only applicable to the construction or infrastructure industry, where a gestation period is necessary allowing the newly developed structure to gradually build up its tenancy and subsequently its cash flows. It can also be used to finance a whole range of ventures such as technology start-ups. Finally, participating loans can also be used in negotiations between borrower and lender to structure a workout loan, whenever lowering rigid interest payments is necessary (see example below).

\subsection{Shared appreciation mortgages}

In this case the lender subsidizes the interest component in return for a share $\theta_{H}$ in the appreciation when the property is sold, under the assumption that the property can only be sold at maturity. That is, the financier trades off interest rate with participation in the appreciation of the property. 9

This yields a reduced contract rate $i$ computed from the general case 10 by setting $\theta_{P}$ to zero

$$
i=r-\frac{r c\left(H_{0}, H_{0}, r, \delta_{H}, \sigma_{H}, T\right)}{\bar{L} H_{0}\left(1-e^{-r T}\right)} \theta_{H} .
$$

The above pricing condition only requires computing the corresponding value of the at-themoney-call option $c$ struck at the initial value of the house $H_{0}$ using the well-known Black Scholes (1973) formula.

Since the above trade-off reduces the high debt payments (of a fixed mortgage loan such as that of a sub-prime), it has the capacity to mitigate default risk and thus help improve the overall efficiency of the financial system.

Shared Appreciation Mortgages can be of service in the residential mortgage market, especially in the current depressed real estate sector. The US Treasury is encouraging the banking industry to

\footnotetext{
${ }^{8}$ Here again, care must be taken to monitor adequate maintenance of property to avoid risk of moral hazard (see Shiller and Weiss (2000); and Sanders and Slawson (2005)).

${ }^{9}$ Care must be taken to monitor adequate maintenance of property to avoid risk of moral hazard (see Shiller and Weiss (2000) as well as Sanders and Slawson (2005)).
} 
come up with pragmatic solutions to avert foreclosure of home loans, whose mortgage payments are 90 days or more past due (see Ishmael and Politi (2008)). A SAM is a viable alternative in areas where home prices are stable. It can also be pursued where home prices have declined and where the borrower is willing to decrease the exercise price of the appreciation option. This will stabilize home prices and consequently help the global economy recover from the crisis .10

Consider a homeowner struggling with annual repayment of $\$ 7000$ p.a. on a standard mortgage set at $10 \%$ on a $70 \%$ LTV loan, agreed for a house worth $\$ 100000$ initially. The lender offers three workout loans with appreciation shares of $25 \%$ and $50 \%$, assuming a 30 year term, a service flow rate of $5 \%$ and a house price volatility of $4 \%$. These payments are illustrated in Table 1 .

\section{INSERT TABLE 1 ABOUT HERE.}

Values of the reduced contract rate $i$ in Table 1 are computed using the expression (11).

Furthermore, the above property of a SAM is highly appealing for prospective low income home-owners. A SAM can help them qualify for a home loan with higher loan to value ratio $\bar{L}$ than an adjustable rate mortgage with a teaser rate. Finally, note that the appreciation parameter can be directly computed as a function of the contract rate sought

$$
\theta_{H}=\frac{\bar{L} H_{0}\left(1-e^{-r T}\right)}{c\left(H_{0}, H_{0}, r, \delta_{H}, \sigma_{H}, T\right)}\left(1-\frac{i}{r}\right) .
$$

In our example this means that if the homeowner can only afford to pay $\$ 5950$ annually, the corresponding shared appreciation will have to be set at $\theta_{H}=57.56 \%$.

The above solution improves on the existing literature which prices PMs using numerical simulation (see e.g. Sanders and Slawson (2005)). It also helps us conceptualize the trade-off between

\footnotetext{
${ }^{10}$ When pricing SAMs for a work-out loan, one should be careful using appraisal based information in the current pricing of properties. This is because the information from appraisals is erroneous and contradicts our initial assumption of accurate method of valuing property. It, thus, biases our pricing mechanism (see Sanders and Slawson, (2005)). One way around this issue is to avail of special techniques developed on extracting information on accurate valuation from appraisal based data (see Geltner et al. (2003)).
} 
the interest rate and appreciation parameters in a consistent manner. However, it does not incorporate prepayment risk, which is crucial in the real world. This problem is dealt with in the next section

\subsection{Shared income mortgages}

It is straightforward to extend our analysis of PMs to commercial mortgages where Shared Income Mortgages (SIMs) play an important role. Profit flow can be shared with the lender to lower the contract rate. The lender is compensated proportionally to the excess intermediate profit flow $\left(P_{t}-K\right)^{+}$where $K$ is the fixed profit threshold above which participation is payable. Unlike Alvayay et al. (2005), whose discrete-time formulation involves finite sums requiring numerical simulation, our analysis uses closed-form solution.

For non-prepayable non-amortizing loans the valuation equation $(10)$ gives

$$
i=r-\frac{r C\left(P_{0}, K, r, \delta, \sigma, T\right)}{Q_{0}\left(1-e^{-r T}\right)} \theta_{P}
$$

This condition gives a simple relationship between reduced interest and participation rate $\left\{i, \theta_{P}\right\}$. Expressing the loan value, so that $Q_{0}=\bar{L} H_{0}$, where $H_{0}$ is the current market value of the property, the lender may fine-tune the loan by offering higher or lower maximum loan-to-value ratios $\bar{L}$. The interpretation of this result is straightforward. The contractual interest rate $i$ (on the mortgage) can be traded-off against a positive participation rate $\theta_{P}>0$. The higher the participation, the greater the reduction in interest rate ${ }^{11}{ }^{12}$ This trade-off has the capacity to reduce defaults and enhance the overall flexibility of the financial system.

The reduction in interest rate can be moderated by higher loan-to-value ratio $\bar{L}$. For sufficiently low $\bar{L}$ and sufficiently high participation $\theta_{P}$ it is possible to achieve $i=0$ and compensate the lender

\footnotetext{
${ }^{11}$ In contrast, variable tenor mortgages described in Chow et al. (2000) have the capacity to only cap the contractual interest rate by automatically stretching the maturity of the contract. Moreover, as the authors point out, industry practice is to introduce a cap on the tenor thereby rendering such contracts similar to variable rate mortgages and therefore losing most of their attractiveness.

${ }^{12}$ In case of SIM, a very high $\theta_{P}$ can introduce the risk of moral hazard, which is opposite to the one elaborated in Shiller and Weiss (2000). Here, an investor can undertake extensive capital improvement to under-represent income and convert the excess income to capital appreciation (which is not shared with the financier).
} 
through profit cap and real estate call alone. At this point all cash flows to the financier become uncertain, contingent on profit flow and there are no fixed interest payments. Fixed income flow is substituted for a risky stream.

It is relatively easy to evaluate the impact of increased time to maturity on the contractual interest rate $i$ by computing the partial derivative

$$
\frac{\partial i}{\partial T}=\frac{r \theta_{P}}{\bar{L} H_{0}} \frac{1}{1-e^{-r T}}\left[\frac{\partial C}{\partial T}-\frac{r e^{-r T}}{1-e^{-r T}} C\right],
$$

where $C=C\left(P_{0}, K, r, \delta, \sigma, T\right)$ is the profit cap given in closed form by (39) where $\lambda$ is set to zero. The term in brackets contains the theta hedge ratio of the cap. It is equal to the expected, discounted terminal caplet payoff on the (unknown) flow $P_{T}$ at time $T$ struck at $K$ (i.e. $\left(P_{T}-K\right)^{+}$discounted at rate $r$ ), which corresponds to evaluating at time $T$ the integrand in the integral appearing in (38) ${ }^{13}$ Evaluating the risk-neutral expectation of the terminal excess profit flow produces the Black-Scholes (1973) formula for European call and is positive

$$
\begin{aligned}
\frac{\partial C}{\partial T} & =e^{-r T} E\left[\left(P_{T}-K\right)^{+}\right]=C\left(P_{0}, K, r, \delta, \sigma, T\right) \\
& =P_{0} e^{-\delta T} \Phi\left(d_{1}^{K, P_{0}}\right)-K e^{-r T} \Phi\left(d_{0}^{K, P_{0}}\right)>0
\end{aligned}
$$

This is because the cap in equation (39) is a time integral of Black-Scholes options $(16)$. The theta is positive in the sense that as the horizon $T$ gets longer by $\Delta t$, the profit cap $C$ becomes more valuable by $C\left(P_{0}, K, r, \delta, \sigma, T\right) \Delta t$. The impact of maturity $T$ on $i$ can thus be obtained by establishing the sign of the term in brackets in (14).

For infinite maturity loans $C\left(P_{0}, K, r, \delta, \sigma, \infty\right)$ does not depend on $T$, implying

$$
\lim _{T \rightarrow \infty} \frac{\partial C}{\partial T}=0 \quad \text { and therefore } \quad \lim _{T \rightarrow \infty} \frac{\partial i}{\partial T}=0,
$$

\footnotetext{
${ }^{13} \mathrm{~A}$ caplet has a payoff which is identical to the payoff of a call option. The difference is that the caplet has for underlying a variable which is a continuous flow $\left(P_{t}\right.$ in our case) in place of a stock for the call option.
} 
as expected i.e. for $T \rightarrow \infty$, the contractual rate $i$ will gradually converge to some $i_{\infty}$ given by

$$
\begin{gathered}
i_{\infty}=r\left[1-\frac{\theta_{P}}{\bar{L} H_{0}} C\left(P_{0}, K, r, \delta, \sigma, \infty\right)\right] . \\
\text { PUt Figure 2] ABOUT Here. }
\end{gathered}
$$

In the example represented on Figure 2 the continuum of caplets on profit flow is initially

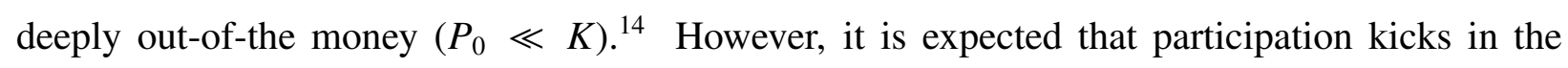
future. Under assumptions of exponentially growing cash flow at the rate $r$ (10\% in our example) it is expected to reach the threshold $K=1000000$ at approximately $t_{K} \approx 14$ years, where $t_{K}$ solves

$$
\begin{aligned}
E\left[P_{t_{K}} \mid P_{0}\right] & =P_{0} \exp \left\{r t_{K}\right\}=K \\
& \Longrightarrow t_{K}=\frac{1}{r} \ln \frac{K}{P_{0}}=\frac{1}{0.1} \ln \frac{1000000}{250000} \approx 13.863
\end{aligned}
$$

Figure 2 further confirms that, independently of the rate of participation $\theta_{P}$, the lender is able to grant a decent discount only if the maturity $T$ of the loan exceeds about 14 years. It is expected that the level of available cash flow to share continues to grow exponentially after $P_{t}$ crosses $K$ from below.

The lender is willing to offer a wider spread between $i$ (the contract rate) and $r$ (the risk free rate, $r=10 \%$ in our example) for higher levels of participation $\theta_{P}$ and for longer maturities $T$. If the maturity $T$ of the loan is very short, the excess profit cash flow is close to zero and the applicable discount is almost inexistent i.e. $i \approx r$.

It should be emphasized that the spread $i-r$ is a fair spread in the sense that it not only rewards for participation (via parameter $\theta_{P}$ in the formula (13) for $i$ ) and time value of money (via parameter $T$ ), but also can be constructed so as to reward default and/or prepayment risks across many such mortgages and lending cycles. This dependence is reflected via prepayment intensity parameter $\lambda$ in (46). The latter is a variant of our formula (13) for $i$. It is analogous to (13) but valid in a context with prepayments. See section 4.2 .

\footnotetext{
${ }^{14}$ See note 13
} 
Alternatively, the participation rate $\theta_{P}$ can be expressed in terms of the contractual interest rate $i$

$$
\theta_{P}=\frac{\bar{L} H_{0}\left(1-e^{-r T}\right)}{C\left(P_{0}, K, r, \delta, \sigma, T\right)}\left(1-\frac{i}{r}\right) .
$$

Clearly, higher loan-to-value ratios $\bar{L}$ necessarily imply higher participation rates $\theta_{P}$. Similarly, the lower the contractual interest rate $i<r$, the higher the participation $\theta_{P}$. Furthermore, impact of variations in time to maturity $T$ or threshold profit flow level $K$ can be assessed by employing appropriate sensitivities of the cap $C$ with respect to underlying variables, which are readily available in closed form (see Shackleton and Wojakowski (2007) for hedge ratios).

\section{Put Figure 3 about here.}

Figure 3 illustrates the dependence of the participation ratio $\theta_{P}$ on maturity $T$. It confirms our intuition that, the longer the maturity of the loan, the lower the participation required to grant the same discount. Similarly, the higher the discount granted the higher the required participation. The dashed line represents the highest discount (no interest charged $i=0$ ) and thus participation here must dominate other offers, when the time to maturity of mortgage loans is kept constant. For loans of maturity $T=40$ years it is sufficient to participate at the level $\theta_{P} \approx 51 \%$ in order to generate full discount $(i=0)$. When time to maturity $T$ approaches zero, $\theta_{P}$ rises very sharply. This is because for shorter maturity loans participation parameter must be substantially higher to compensate for discount $r-i$ granted. To better illustrate this, logarithmic scale is used for $\theta_{P}$.

\subsection{Shared equity mortgages}

For Shared Equity Mortgages (SEMs), we assume that the borrower needs $H_{0}$ at the onset in order to start a commercial activity or make a step on the property ladder. The lender accepts an amount $D_{0}$, which in a strict sense is not a deposit, but his initial share (equity) and lends $Q_{0}$ to him. Note in particular that $Q_{0}<H_{0}$. Since coupon payments are waived $(i=0)$ in a SEM, the financier will require different forms of compensation. These are provided by participation in 
the profit flow $P$ above some threshold level $K$ as well as participation in the appreciation of the property value $H$. The intermediate cash flow rate is $\theta_{P}\left(P_{t}-K\right)^{+}$. The terminal cash flow consists of the remaining capital $Q_{T}$ plus the fraction $\theta_{H}$ of the appreciation, if positive, in the value of property $\left(H_{T}-H_{0}\right)^{+}$, payable to the lender. In absence of prepayments $(\lambda=0)$ condition $(8)$ then gives

$$
Q_{0}=\theta_{P} \int_{0}^{T} e^{-r t} E\left[\left(P_{t}-K\right)^{+}\right] d t+e^{-r T} E\left[Q_{T}\right]+\theta_{H} e^{-r T} E\left[\left(H_{T}-H_{0}\right)^{+}\right]
$$

Two option components are present here. The first is linked to generation of intermediate profits by the occupier and is a continuous sum of discounted intermediate payments. The second, discrete and terminal optional component, uses real estate appreciation as ultimate mean of mortgage repayment.

For non-amortizing mortgages (21) gives

$$
Q_{0}=\theta_{P} C\left(P_{0}, K, r, \delta, \sigma, T\right)+e^{-r T} Q_{0}+\theta_{H} c\left(H_{0}, H_{0}, r, \delta_{H}, \sigma_{H}, T\right),
$$

where $C$ represents the profit cap function (39) (described below), while $c$ represents a European call option on real estate $H$ issued at the money. It can be computed as

$$
c\left(H_{0}, H_{0}, r, \delta_{H}, \sigma_{H}, T\right)=H_{0}\left[e^{-\delta_{H} T} \Phi\left(d_{1}^{H_{0}, H_{0}}\right)-e^{-r T} \Phi\left(d_{0}^{H_{0}, H_{0}}\right)\right],
$$

where

$$
d_{\beta}^{H_{0}, H_{0}}=\frac{\left(r-\delta_{H}+\left(\beta-\frac{1}{2}\right) \sigma_{H}^{2}\right) T}{\sigma_{H} \sqrt{T}} \quad \beta=0,1 .
$$

Since all quantities in (22) are easy to compute, analysis of a SEM is simple. In particular (22) allows expressing the profit participation ratio $\theta_{P}$ as function of real estate participation ratio $\theta_{H}$

$$
\theta_{P}=\frac{\bar{L} H_{0}\left(1-e^{-r T}\right)-\theta_{H} c\left(H_{0}, H_{0}, r, \delta_{H}, \sigma_{H}, T\right)}{C\left(P_{0}, K, r, \delta, \sigma, T\right)},
$$

where it is assumed as usual that the debt capacity is set at $Q_{0}=\bar{L} H_{0} \sqrt{15}$ Since all quantities

\footnotetext{
${ }^{15}$ Here too, one needs to be careful of the risk of moral hazard, where investors frivolously spend on capital im-
} 
appearing in 25 are positive, we realize that the higher the real estate participation $\theta_{H}$, the lower the profit participation $\theta_{P}$. For a given real estate participation $\theta_{H}$ ratio, sensitivities of profit participation $\theta_{P}$ to tenure $T$, interest rate level $r$, loan-to-value ratio $\bar{L}$ or house price level $H_{0}$ can be computed in closed form. For example the sensitivity of the profit participation $\theta_{P}$ to house price level $H_{0}$ is given by

$$
\frac{\partial \theta_{P}}{\partial H_{0}}=\frac{\bar{L}\left(1-e^{-r T}\right)-\theta_{H} \Delta_{c}(T)}{C\left(P_{0}, K, r, \delta, \sigma, T\right)},
$$

where $\Delta_{c}(T)$ is the delta of an at-the-money call option

$$
\Delta_{c}(T)=\Phi\left(\left(r-\delta_{H}+\frac{1}{2} \sigma_{H}^{2}\right) \frac{\sqrt{T}}{\sigma_{H}}\right) .
$$

Note that $\Delta_{c}(T)$ is independent of the current level of a house price index $H_{0}$ as the mortgage is set initially at-the-money. These quantities may be very useful in structuring characteristics of a SEM contracts in practice. For example, in order to immunize $\theta_{P}$ to the initial real estate price risk, $\left\{\theta_{H}, \theta_{P}\right\}$ should be set so that

$$
\left\{\begin{array}{l}
\theta_{H}^{*}=\frac{\bar{L}\left(1-e^{-r T}\right)}{\Delta_{c}(T)} \\
\theta_{P}^{*}=\left[H_{0}-\frac{c\left(H_{0}, H_{0}, r, \delta_{H}, \sigma_{H}, T\right)}{\Delta_{c}(T)}\right] \frac{\bar{L}\left(1-e^{-r T}\right)}{C\left(P_{0}, K, r, \delta, \sigma, T\right)}
\end{array}\right.
$$

This result has been obtained by differentiating $\theta_{P}$ given by equation 25 with respect to $H_{0}$ (see (26)), setting this derivative to zero and solving for $\theta_{H}^{*}$. The corresponding $\theta_{P}^{*}$ was obtained by inserting $\theta_{H}^{*}$ in 25$)$. We observe that $\theta_{H}^{*}$ is then independent of $H_{0}$, while $\theta_{P}^{*}$ is decreasing in $H_{0}$ (see Figure 4).

\section{Put Figure 4 about HeRe.}

provements, which may not help in the appreciation of the property but may be for personal consumption. This situation is opposite to that reported in Shiller and Weiss (2000) but is akin to the case of "hubris" identified in the corporate takeover literature (see Roll (1986)). 


\section{Refinancing and prepayment of participating mortgages}

Refinancing constitutes a major risk faced by financial institutions as it leads to termination of profitable businesses at inopportune moments. Lenders also face prepayment risk because they don't know for how long a loan will be outstanding. Financial institutions can mitigate this risk by imposing a penalty to deter potentially mobile borrowers or those who flip property frequently. The penalty in this section is designed so that to mimic those found in alternative mortgages like subprime (see Chomsisengphet and Pennington-Cross (2006)) and is in the spirit of Stanton and Wallace (1998). It can be evaluated using the methodology described below.

Empirical evidence confirms that borrowers do not prepay optimally, i.e. they do not maximize the loss to the lender. Reasons for prepaying typically include a sale of the property due to: a) change of employment; b) change in family composition (e.g. births, children leaving for university); c) a natural disaster, accident or default of the borrower followed by insurance indemnity payment. These factors are relatively stationary in time and are often modelled in the mortgage industry using the constant conditional prepayment rate (CPR) convention or the Public Securities Association (PSA) benchmark (see e.g. Fabozzi (2005)). These professional conventions do not explicitly model prepayments due to refinancings which typically occur at an increased rate during periods of decreasing interest rates.

Prepayments can be modelled using a hazard rate (prepayment intensity) approach. The random prepayment time $\tau_{p}$ is modelled as a Poisson process with intensity $\lambda$ and is independent of state variables governing the processes for income and house prices. Formally, information in the model is described by enlarged filtration $\mathcal{G}$, generated by both Brownian motions $Z_{t}$ and $Z_{t}^{H}$ and the prepayment indicator process $\mathbf{1}_{\left\{\tau_{p} \geq t\right\}}$ (see e.g. Bielecki and Rutkowski (2002)).

Financial institutions typically impose a dollar prepayment penalty $\Pi_{\tau_{p}}$. It is often a fraction $\alpha$ of the principal outstanding $Q_{\tau_{p}}$ and is imposed if refinancing occurs before some lock-in date $T^{*}$. 
This gives

$$
\Pi_{\tau_{p}}=\alpha Q_{\tau_{p}} \mathbf{1}_{\tau_{p}<T^{*}}=\left\{\begin{array}{cl}
\alpha Q_{\tau_{p}} & \text { if } \tau_{p}<T^{*} \\
0 & \text { otherwise. }
\end{array}\right.
$$

The prepayment penalty caters to only serious long term investors who like to match the cost of financing with the income and the growth in the value of the asset instead of just their permanent income in case of alternative mortgages (see Hurst and Stafford (2004); Doms and Krainer (2007)).

In practice, the contract is negotiated so that no prepayment can occur immediately. Therefore, the value of the mortgage at origination, $M_{0}$, must then be equal to the expected value of outstanding cash flows

$$
M_{0}=E\left[\int_{0}^{T} F(t) e^{-r t} c_{t} d t+\int_{0}^{T} g(t) e^{-r t} S_{t} d t+F(T) e^{-r T} S_{T}\right] \text {, }
$$

where

$$
F(t)=\operatorname{Pr}\left(t<\tau_{p}\right)=e^{-\lambda t}
$$

is the cumulative probability of the loan surviving beyond time $t, g(t)$ is the probability density of the loan being prepaid within time interval $[t, t+d t]$ i.e.

$$
g(t)=\frac{d}{d t}(1-F(t))=\lambda e^{-\lambda t}, \text { and }
$$

- $c_{t}$ is the value of continuous payments received until prepayment date or maturity, whichever comes first, equal to interest plus income participation

$$
c_{t}=i Q_{t}+\theta_{P}\left(P_{t}-K\right)^{+}
$$

- $S_{t}$ is the lump sum payment received if prepayment occurs before maturity, and is equal to appreciation participation plus principal outstanding $Q_{t}$ plus applicable prepayment penalty $\Pi_{t}$ (if any);

$$
S_{t}=\theta_{H}\left(H_{t}-H_{0}\right)^{+}+Q_{t}+\Pi_{t}
$$

- $S_{T}$ is the lump sum payable at the tenure of the PM (defined in the indenture of the contract) 
if prepayment did not occur, i.e. any capital outstanding plus appreciation participation ${ }^{16}$

$$
S_{T}=\theta_{H}\left(H_{T}-H_{0}\right)^{+}+Q_{T}
$$

Note that this implies that if prepayment did not occur before maturity, the principal and participation must be repaid in full.

As long as prepayment does not occur early $\left(t<\tau_{p}\right)$ the lender receives $c_{t}$ (i.e., both the contractual interest flow and also the income participation flow provided that $P_{t}$ is above the threshold $K)$. Furthermore, if prepayment does not occur before maturity $\left(T<\tau_{p}\right)$, the lender receives the principal and the fractional appreciation (if any), as lump sums on maturity. Otherwise, if prepayment occurs at time $\tau_{p} \in(0, T)$, both interest and income participation flows cease immediately and the lender receives a lump sum corresponding to the property's fractional appreciation (if any), principal payback and prepayment penalty (if any).

Using (31) and (32) in 30) the value of the mortgage at origination can be shown to be equal to

$$
M_{0}=E\left[\int_{0}^{T} e^{-(r+\lambda) t}\left(c_{t}+\lambda S_{t}\right) d t+e^{-(r+\lambda) T} S_{T}\right]
$$

For non-amortizing loans for which $Q_{t}=Q_{0}$ for all $t \in[0, T]$ it is quite straightforward to compute this expectation to obtain the general PM valuation equation

$$
\begin{aligned}
M_{0} & =i Q_{0} \frac{1-e^{-(r+\lambda) T}}{r+\lambda}+\theta_{P} C\left(P_{0}, K, r+\lambda, \delta+\lambda, \sigma, T\right) \\
& +\theta_{H} C\left(\lambda H_{0}, \lambda H_{0}, r+\lambda, \delta_{H}+\lambda, \sigma_{H}, T\right)+\lambda Q_{0} \frac{1-e^{-(r+\lambda) T}}{r+\lambda}+\lambda \alpha Q_{0} \frac{1-e^{-(r+\lambda) T^{*}}}{r+\lambda} \\
& +\theta_{H} c\left(H_{0}, H_{0}, r+\lambda, \delta_{H}+\lambda, \sigma_{H}, T\right)+Q_{0} e^{-(r+\lambda) T},
\end{aligned}
$$

$T^{*}$ is the last date $\Pi_{\tau_{p}}$ is chargeable and $c\left(H_{0}, H_{0}, r+\lambda, \delta_{H}+\lambda, \sigma_{H}, T\right)$ is the value of an at-themoney European call option on the property multiplied by the probability of the mortgage loan

\footnotetext{
${ }^{16}$ We assume that if prepayment occurs, the property is either sold or appraised revealing its value $H_{\tau_{p}}$ or $H_{T}$. Alternatively, a house price index of the locality can be used to estimate the appreciation.
} 
surviving until maturity time $T$

$$
c\left(H_{0}, H_{0}, r+\lambda, \delta_{H}+\lambda, \sigma_{H}, T\right)=e^{-\lambda T} c\left(H_{0}, H_{0}, r, \delta_{H}, \sigma_{H}, T\right) .
$$

The main difficulty in (37) is computing expressions giving the cap value

$$
C\left(X_{0}, k, \varrho, \phi, \sigma, T\right)=\int_{0}^{T} E\left[e^{-\varrho t}\left(X_{t}-k\right)^{+}\right] d t=\int_{0}^{T} e^{-\lambda t} E\left[e^{-r t}\left(X_{t}-k\right)^{+}\right] d t,
$$

where $\varrho=r+\lambda$ and $\phi=\delta+\lambda$ or $\phi=\delta_{H}+\lambda$ i.e. sums of caplets on $X$ struck at $k$ over a continuum of maturities $t \in[0, T]$. In the last integral in (38) each caplet is weighted by the probability $e^{-\lambda t}$ that the loan will "survive" beyond $t$. This is because each $\left(X_{t}-k\right)^{+}$will be due only if the loan was not prepaid before $t$. These sums can be interpreted as weighted caps on either the income flow $P_{t}$ or a flow generated by prepaid "fraction" of the property value $\lambda H_{t}$.

It can be shown that weighted caps have the following closed-form solution (see Shackleton and Wojakowski (2007)):

$$
\begin{aligned}
C\left(X_{0}, k, \varrho, \phi, \sigma, T\right) & =A_{1} X_{0}\left(\mathbf{1}_{X_{0} \geq k}-e^{-\phi T} N\left(d_{1}\right)\right)-A_{0}\left(\mathbf{1}_{X_{0} \geq k}-e^{-\varrho T} N\left(d_{0}\right)\right) \\
& +A_{b} X_{0}^{b}\left(\mathbf{1}_{X_{0} \geq k}-N\left(d_{b}\right)\right)-A_{a} X_{0}^{a}\left(\mathbf{1}_{X_{0} \geq k}-N\left(d_{a}\right)\right)
\end{aligned}
$$

where

$$
\begin{aligned}
a, b & =\frac{1}{2}-\frac{\varrho-\phi}{\sigma^{2}} \pm \sqrt{\left(\frac{1}{2}-\frac{\varrho-\phi}{\sigma^{2}}\right)^{2}+\frac{2 \varrho}{\sigma^{2}}} \\
d_{\beta} & =\frac{\ln X_{0}-\ln k+\left(\varrho-\phi+\left(\beta-\frac{1}{2}\right) \sigma^{2}\right) T}{\sigma \sqrt{T}},
\end{aligned}
$$

for $\beta \in\{0,1, a, b\}$ and

$$
A_{a}=\mathcal{A}(a, b) \quad A_{b}=\mathcal{A}(b, a) \quad A_{1}=\mathcal{A}(1,0) \quad A_{0}=\mathcal{A}(0,1)
$$

where

$$
\mathcal{A}(x, y)=\frac{k^{1-x}}{|x-y|}\left(\frac{y}{\varrho}-\frac{y-1}{\phi}\right) .
$$


Furthermore, in order to eliminate arbitrage the value of the mortgage at origination, $M_{0}$, must then be equal to the value of the loan outstanding, $Q_{0}$. Solving this condition, i.e. $Q_{0}=M_{0}$, where $M_{0}$ is given by (37) above, enables to represent key parameters of the contract, such as the contract rate $i$ or participation ratios $\theta_{P}$ and $\theta_{H}$, as functions of market data and other inputs or constraints. We will focus on this problem in sections that follow.

Finally, notice that both of the professional conventions (CPR and PSA) assume the prepayment rate $\lambda$ is constant in time and independent of the interest rate $r$. In practice, however, $\lambda$ will be influenced by the level of interest rates. To illustrate this dependence it is possible to set a timedependent $\lambda_{t}=\lambda\left(t, r_{t}\right)$ so that it is equal to a prepayment intensity $\lambda_{p}$ plus a refinancing intensity $\lambda_{r}$, for example 17

$$
\lambda_{t}=\lambda_{p}+\lambda_{r}=\lambda_{p}+l_{r}\left(\bar{r}-r_{t}\right)^{+}
$$

The first term caters for prepayments due to purely exogenous, structural reasons such as relocations. The second term accounts for refinancings due to decreasing interest rate $r_{t}$, so that homeowners intensify their refinancing as interest rates decrease. The decrease in interest rates is translated into a higher refinancing component via the refinancing parameter $l_{r}$ which acts as multiplier. By contrast, when interest rates exceed some higher threshold $\bar{r}$, the prepayment incentive motivated by refinancings disappears. Typically, $\bar{r}<r_{0}$ initially, so that $\left(\bar{r}-r_{0}\right)^{+}=0$ and there is no incentive to refinance at origination.

\subsection{Shared appreciation mortgages and prepayments}

To illustrate PM valuation in a world with prepayment risk, we focus on the case of a SAM for which $\theta_{P}=0$. This case is particularly important for residential mortgages for which only future house appreciation is contractually shared without sharing individual income as it might be difficult to contract on human capital. Note that unlike the case without prepayment, valuation now depends on the sum of caplets (representing appreciation participation, if any) weighted by the

\footnotetext{
${ }^{17}$ See e.g. Gorovoy and Linetsky (2007).
} 
probability of the mortgage "surviving" over the time period $[0, T)$. This quantity is analytically expressed by the cap function $C\left(\lambda H_{0}, \lambda H_{0}, r+\lambda, \delta_{H}+\lambda, \sigma_{H}, T\right)$. When $\lambda=0$ (no prepayment) this quantity is equal to zero.

Some key parameters can be expressed explicitly. For example, given parameters such as the prepayment rate $\lambda$, prepayment penalty fraction $\alpha$ and lock-in time $T^{*}$ we can explicitly compute the contract rate $i$ as follows

$$
\begin{aligned}
i= & r-\theta_{H} \frac{r+\lambda}{Q_{0}\left(1-e^{-(r+\lambda) T}\right)} \times \\
& \times\left[C\left(\lambda H_{0}, \lambda H_{0}, r+\lambda, \delta_{H}+\lambda, \sigma_{H}, T\right)+c\left(H_{0}, H_{0}, r+\lambda, \delta_{H}+\lambda, \sigma_{H}, T\right)\right] \\
& -\lambda \alpha \frac{1-e^{-(r+\lambda) T^{*}}}{1-e^{-(r+\lambda) T}},
\end{aligned}
$$

where $\alpha$ and $T^{*}$ capture the prepayment penalty $\Pi_{\tau_{p}}$. This equation implies that the higher the participation proportion $\theta_{H}$, the lower is the contract rate $i$. Likewise, the contract rate $i$ can be decreased by higher prepayment penalties $\alpha$. A further reduction in the contract rate $i$ is achieved by extending the lock-in period $T^{*}$ towards maturity $T$. Finally, we observe that for $\lambda=0$ (implying no prepayment penalty) this expression for the contract rate $i$ converges to the result (11) discussed before.

To illustrate the sensitivity of the contract rate $i$ to various inputs we present a numerical example assuming the following base case:

$\begin{array}{lrrl}\text { initial loan value } & Q_{0} & \$ 70000 & \\ \text { initial house price } & H_{0} & \$ 100000 & \\ \text { market interest rate } & r & 10 \% & \text { p.a. } \\ \text { service flow rate } & \delta_{H} & 5 \% & \text { p.a. } \\ \text { house price volatility } & \sigma_{H} & 4 \% & \text { p.a. } \\ \text { term } & T & 30 & \text { years }\end{array}$

We further assume that an individual (initially paying $\$ 7000$ per annum on a standard $10 \%$ mort- 
gage loan) also has problems with paying off his loan. That is, he cannot afford the $\$ 7000$ per year and is inclined to accept alternative offers from a bank in order to reduce his debt burden. A zero-profit bank offers a set of alternative mortgages, including 25\% and 50\% SAMs. Table 2 summarizes contracts offered to this individual.

\section{INSERT TABLE 2 ABOUT HERE.}

There are three families of contracts. "Type 0" column contains contracts which do not include any prepayment penalties. "Type 1" contracts include a small prepayment penalty $(\alpha=1 \%$ of balance outstanding for the first $T^{*}=5$ years) while "Type 2" contracts include a harsher penalty ( $\alpha=5 \%$ of balance outstanding for the first $T^{*}=5$ years).

Each of the three families of contracts contains a standard (i.e. 0\% appreciation) loan as well as a $25 \%$ and a $50 \%$ SAMs. Furthermore, each of these contracts is then priced using the formula (45) for SAMs with various prepayment rates to obtain the contract rate $i$ and the corresponding annual repayment amount $i Q_{0}$. To see how the characteristics of the individual influence the fair pricing of these products, computations are done for four types of individuals, according to how likely they are to prepay their mortgage. We use 50\%, 100\%, 200\% and 400\% multiples of the long-term standard PSA value of $6 \%$ annual prepayment rate $(\lambda=0.06)$. This results in values for $\lambda$ which are 0.03 (less likely to prepay than average), 0.06 (average), 0.12 (twice more likely to prepay as average) and 0.48 (four times more likely to prepay compared to average).

Examination of Table2 tells us that it is difficult for the bank to offer an attractive workout loan based on prepayment penalty alone, unless the penalty is really harsh $(\alpha=5 \%)$ and the individual is assumed to be really impatient (400\% PSA). Then the contract rate can be lowered from $10 \%$ to $7.73 \%$ and the annual repayment reduced from $\$ 7000$ to $\$ 5412.44$. However, even individuals less likely to prepay early (50\% PSA) can be offered reduced interest if they opt for a SAM feature. For example a contract rate of $8.24 \%$ can be offered for a $50 \%$ SAM without imposing any early prepayment penalties. 
It is interesting to notice that reductions obtained using both Shared Appreciation feature and early prepayment penalties can be quite considerable. The lowest rate is $4.44 \%$ for a $50 \% \mathrm{SAM}$ with highest (5\%) prepayment penalties and high prepayment rate $\lambda=0.48$ (PSA 400\%). This means that an individual offered such a workout loan will have very high incentives to change his impatient behaviour in order to stay in the property for longer at very low cost. This gives an idea of the characteristics of an individual who would choose this product. Generally, compared to an "average" individual for which the product will be priced, the more an individual is committed to staying longer in the house and committed to services provided by the house (rather than interested in the property as an investment vehicle), the more the product is attractive.

\section{InSERT Figure 5 about here.}

Table 2 should be examined in conjunction with Figure 5 which presents the dependence of mortgage rate $i$ on prepayment intensity $\lambda$ for a standard $10 \%$ contract and a $25 \%$ SAM. Both mortgages are considered with and without an early prepayment penalty. The SAM is a relatively low participation case and the early prepayment penalty used in this example is quite strong: $\alpha=5 \%$ of mortgage balance applicable for the first $T^{*}=5$ years. Generally, SAMs outperform standard mortgages in terms of contract rates $i$, except in the region of high prepayment rates, where a SAM without prepayment penalties is outperformed by a standard loan with such prepayment penalties added.

INSERT Figure 6 about Here.

Figure 6 illustrates the effect of changing prepayment intensity on mortgage values. A $25 \%$ SAM without prepayment penalties is offered for a term of 30 years. From Table 2 the initial contract rate for this mortgage is $8.95 \%$. This is the equilibrium rate which exactly corresponds to the initial mortgage value of $\$ 70000$. However, if the characteristics of the individual change, the mortgage value will change. As illustrated in Figure, if the likelihood of the individual to prepay 
the mortgage increases, the value of this mortgage to the lender will initially increase to attain a maximum. It will then decrease back to $\$ 70000$ for very high values of $\lambda$. Such behaviour of the mortgage value can only be explained in conjunction with explaining the value of the refinanced property to the lender. Because the property offers the homeowner a continuous stream of consumption benefits $\delta A_{t}$ for as long as he occupies the property, the value of the refinanced property to the lender depends on expected time of prepayment $\hat{\tau}_{p}$ and can be approximately illustrated as an European call option with maturity $\hat{\tau}_{p}$ and strike price $H_{0}$. The dependence of such an option on $\hat{\tau}_{p}$ is not monotonic because $\delta_{H}>0$. When $\hat{\tau}_{p}$ increases, the value of such an option will initially increase to attain a maximum. It will then decrease to zero as $\hat{\tau}_{p} \rightarrow \infty$. In our case the maximum of the European call is attained for a certain maturity $\hat{\tau}_{p}^{*} \approx 13.86$ years.

Because the expression for SAM's value contains a European call option value, a SAM will inherit this intermediate maximum feature. Because the European call option value is weighted by a negative exponential function $e^{-\lambda T}$, which reflects the fact that longer maturity calls have lower probability of surviving, the maximum of the cap will be shifted towards the origination date of the mortgage. In our case the maximum of the weighted European call is attained for maturity $T \approx 7.49$ years, which is very close to the maximum of the SAM which is attained for $T \approx 6.89$ years.

In our case the mortgage is initially issued assuming $\lambda=0.06$, which corresponds to expected prepayment arriving in $\lambda^{-1} \approx 16.67$ years. Increasing $\lambda$ will decrease the expected time to prepayment and will result in SAM initially appreciating in value. In our case increase will progress until $\lambda$ attains a value of approximately $\lambda \approx 0.22$ i.e. when prepayment is expected in $\lambda^{-1} \approx 4.54$ years. It can also be verified that for $\lambda$ increasing to infinity, the value of the SAM must progressively decrease to $\$ 70000$. This is because when $\lambda \rightarrow \infty$ the prepayment is immediate. In the absence of arbitrage and lack of prepayment penalties, we recover the initial value of the loan. On the other hand when $\lambda$ decreases to zero the value of the SAM decreases to $\$ 67346$. The interpretation of this is a net present value gain of $\$ 70000-\$ 67346=\$ 2654$ to the borrower, if he "survives" and 
never prepays by waiting until the contractual maturity of $T=30$ years.

\subsection{Shared income mortgages and prepayments}

The general PM valuation equation (37) can be specified for SIMs

$$
i=r-\theta_{P} \frac{r+\lambda}{Q_{0}\left(1-e^{-(r+\lambda) T}\right)} C\left(P_{0}, K, r+\lambda, \delta+\lambda, \sigma, T\right)-\lambda \alpha \frac{1-e^{-(r+\lambda) T^{*}}}{1-e^{-(r+\lambda) T}} .
$$

This expression is very similar to $(45)$ except that, in place of the weighted cap $C$ on the "prepayment flow" $\lambda H$ struck at the money, there is a weighted cap $C$ on the income flow $P$ struck at $K$. This is to be expected because the product now involves participation in the income flow $P$ and not in appreciation of the initial value of the property $H_{0}$. Similarly, the European call $c$ on terminal property value will not be present in equation (46), because there is no appreciation participation here, even if the mortgage attains maturity without being prematurely prepaid or refinanced.

\subsection{Shared equity mortgages and prepayments}

Whenever setting the contract rate to zero is desirable (e.g. $i=0$ in Islamic mortgages), the valuation equation (37) will provide a relationship between $\theta_{H}$ and $\theta_{P}$ which can be represented explicitly as, for example

$$
\begin{aligned}
\theta_{P} & =\frac{1}{C\left(P_{0}, K, r+\lambda, \delta+\lambda, \sigma, T\right)}\left\{\frac{Q_{0}}{r+\lambda}\left[\left(1-e^{-(r+\lambda) T}\right) r-\lambda \alpha\left(1-e^{-(r+\lambda) T^{*}}\right)\right]\right. \\
& \left.-\theta_{H}\left[c\left(H_{0}, H_{0}, r+\lambda, \delta_{H}+\lambda, \sigma_{H}, T\right)+C\left(\lambda H_{0}, \lambda H_{0}, r+\lambda, \delta_{H}+\lambda, \sigma_{H}, T\right)\right]\right\} .
\end{aligned}
$$

Other early prepayment and refinancing structures are also possible within our framework.

\section{Concluding remarks}

An efficient mortgage finance system is an essential ingredient for economic development and consequently its growth. Jaffee and Renaud (1997) articulate its importance as follows: 
Mortgage market development is likely to be a key factor in overall financial market development. In particular, an efficient mortgage market will act as a positive externality for the other capital markets, creating pressure for higher efficiency in these markets. On the other hand, a poorly functioning mortgage market is likely to 'pollute' other financial markets with its inefficiency.

The recent sub-prime crisis and its deteriorating impact on the global economy exemplify their assertions

This paper shows how to improve the flexibility of the mortgage finance system by describing innovative facilities in the form of participating mortgages. In accordance with the prognosis of Sheng (1997) and Renaud (2009), these instruments have the capacity to manage risk at the microeconomic level with the potential for reducing default at the macro-economic level. They are more appealing than convertible mortgages as they are more versatile and retain features of debt through the tenure of the facility, while decreasing dilution of investor control rights.

We proceeded systematically by investigating different variants of participating mortgages (Shared Income, Shared Appreciation and Shared Equity Mortgages) and demonstrate that the closed-form profit cap formulae allow tractability.

We thus contribute by evaluating closed-form finite maturity pricing conditions, which are scarce in real estate finance. We also focus on random tenure mortgages, which arise in the context of default and prepayment risk. Furthermore we illustrate the general applicability of the variants of a PM in a range of projects ranging from infrastructure to technology start-up's. Finally we illustrate the employment of PMs as work-out loans, especially in the recent sub-prime crisis.

A PM is basically a financial innovation that considers the income in addition to the appreciation in value of the property not just the borrowers permanent income (see Hurst and Stafford (2004) and Doms and Krainer (2007)). We price SIM, SEM and SAM variants to demonstrate that a PM is more affordable than comparable alternative mortgages. This is because a PM yields a menu of lower debt payments to be traded off against income and potential appreciation of the 
property.

We conclude that a PM is able to reduce the down payment and income constraints better than alternative mortgages without conveying the risk of the real estate venture to the financial institution. They can cope with negative equity and serve to improve the efficiency of the financial intermediation system (in the sense of Blejer (2006)). This is because of their capacity to share risk at the microeconomic level thereby reducing the fragility and the systemic risk at the macroeconomic level in accordance with the prognosis of Sheng (1997) and Renaud (2009). PMs should therefore be adopted as a primary financing facility as well as for workouts. 


\section{References}

Alvayay, J.R., Harter, C., Smith, W.S., 2005. A theoretic analysis of extent of lender participation in a participating mortgage. Review of Quantitative Finance and Accounting 25, 383-411.

Bielecki, T.R., Rutkowski, M., 2002. Credit Risk: Modeling, Valuation and Hedging. Springer-Verlag, Berlin.

Black, F., Scholes, M., 1973. The pricing of options and corporate liabilities. Journal of Political Economy 81, $637-654$.

Blejer, M., 2006. Economic growth and the stability and efficiency of the financial sector. Journal of Banking and Finance 30, 3429-3432.

Campbell, J.Y., 2006. Household finance. Journal of Finance 61, 1553 - 1604.

Campbell, J.Y., Cocco, J.F., 2003. Household risk management and optimal mortgage choice. Quarterly Journal of Economics 118, 1449-1494.

Caplin, A., Carr, J.H., Pollock, F., Tong, Z.Y., Tan, K.M., Thampy, T., 2007. Shared-equity mortgages, housing affordability, and homeownership. Housing Policy Debate (Fannie Mae Foundation) 18, 209-242.

Capozza, D.R., Kazarian, D., Thomson, T.A., 1998. The conditional probability of mortgage default. Real Estate Economics 26, 359-389.

Carr, P., Lipton, A., Madan, D., 2000. Going with the flow: Alternative approach for valuing continuous cash flows. Risk 13, 85-89.

Chomsisengphet, S., Pennington-Cross, A., 2006. The evolution of the subprime mortgage market. Federal Reserve Bank of St. Louis Review , 31-56.

Chow, Y.F., Huang, C., Liu, M., 2000. Valuation of adjustable rate mortgages with automatic stretching maturity. Journal of Banking \& Finance 24, 1809-1829.

Daglish, T., 2009. What motivates a subprime borrower to default? Journal of Banking and Finance 4, 681-693.

Doms, M., Krainer, J., 2007. Innovations in mortgage markets and increased spending on housing. Working paper, Federal Reserve Board of San Francisco.

Dougherty, A., Van Order, R., Villani, K., 1982. Pricing shared-appreciation mortgages. Housing Finance Review 1, $361-375$.

Ebrahim, M., Hussain, S., 2010. Financial development and asset valuation: The special case of real estate. Journal of Banking and Finance 34, 150-162.

Ebrahim, M.S., 1996. On the design and pareto-optimality of participating mortgages. Real Estate Economics 24, 407-419.

Fabozzi, F., 2005. The Handbook of Fixed Income Securities. McGraw Hill, New York. 
Freiberg, L., 1982. The problem with SAM: An economic and policy analysis. Housing Finance Review 1, 73-91.

French, D.W., Haney, Jr., R.L., 1984. Pricing the shared-appreciation mortgage in a stochastic environment. Housing Finance Review 3, 431-443.

Geltner, D., MacGregor, B.D., Schwann, G.M., 2003. Appraisal smoothing and price discovery in real estate markets. Urban Studies 40, 1047-1064.

Glaeser, E.L., 2007. Sensible solutions to the lending mess. The Boston Globe September 7.

Gorovoy, V., Linetsky, V., 2007. Intensity-based valuation of residential mortgages: An analytically tractable model. Mathematical Finance 17, 541-573.

Hurst, E., Stafford, F., 2004. Home is where the equity is: Mortgage refinancing and household consumption. Journal of Money, Credit, and Banking 36, 985-1014.

Ishmael, S.M., Politi, J., 2008. Lifeline thrown to foundering borrowers. Financial Times February 14, 9.

Jaffee, D., Renaud, B., 1997. Strategies to develop mortgage markets in transition economies, in: Doukas, J., Murinde, V., Wihlborg, C. (Eds.), Financial Sector Reform and Privatization in Transition Economies. Elsevier Science B. V., Netherlands, pp. 69-93.

Kau, J.B., Keenan, D.C., Muller, W.J., Epperson, J.F., 1992. A generalized valuation model for fixed-rate residential mortgages. Journal of Money, Credit and Banking 24, 279-299.

Khandani, A.E., Lo, A.W., Merton, R., 2009. Systemic risk and the refinancing ratchet effect. Working paper, Sloan School of Management, MIT.

Krainer, J., Marquis, M., 2004. Mortgages as recursive contracts. Working paper, Federal Reserve Board of San Francisco.

LaCour-Little, M., Rosenblatt, E., Yao, V., 2009. Follow the money: A close look at recent southern california foreclosures. Working paper, California State University-Fullerton.

Lee, C., Lee, K., Yeo, G., 2009. Investor protection and convertible debt design. Journal of Banking and Finance 33, 985-995.

Lekkas, V., Quigley, J., Van Order, R., 1993. Loan loss severity and optimal mortgage default. Journal of the American Real Estate and urban Economic Association 21, 353-371.

Levine, R., Loayza, N., Beck, T., 2000. Financial intermediation and growth: Causality and causes. Journal of Monetary Economics 46, 31-77.

Merton, R.C., 1976. Option pricing when underlying stock returns are discontinuous. Journal of Financial Economics $3,125-144$.

Mian, A.R., Sufi, A., 2009. House Prices, Home Equity-Based Borrowing, and the U.S. Household Leverage Crisis. 
American Economic Review, forthcoming. Chicago Booth Research Paper No. 09-20.

Modigliani, F., 1974. Some economic implications of the indexing of financial assets with special reference to mortgages. Paper Presented at the Conference on the New Inflation, Milano, Italy, June 24-26.

Murphy, J.A., 1990. A practical analysis of shared-appreciation mortgages. Housing Policy Debate 2, 43-48. Office of Housing Policy Research, Fannie Mae, Washington.

Myers, S., 1977. Determinants of corporate borrowing. Journal of Financial Economics 5, 147-175.

Page, F.H., Sanders, A.B., 1986. On the pricing of shared-appreciation mortgages. Housing Finance Review (now Journal of Housing Economics) 5, 49-57.

Qi, M., Yang, X., 2009. Loss given default of high loan-to-value residential mortgages. Journal of Banking and Finance 33, 788-799.

Reinhart, C.M., Rogoff, K.S., 2008a. Banking crisis: An equal opportunity menace. Working Paper, Harvard University.

Reinhart, C.M., Rogoff, K.S., 2008b. Is the 2007 u.s. sub-prime financial crisis so different? an international historical comparision. Working Paper, Harvard University.

Renaud, B.M., 2009. Mortgage finance in emerging markets: Constraints and feasible development paths, in: Mortgage Markets Worldwide. Blackwell. chapter 11, pp. 253-288.

Roll, R., 1986. The hubris hypothesis of corporate takeovers. Journal of Business 59, 197-216.

Sanders, A.B., V. Carlos Slawson, J., 2005. Shared appreciation mortgages: Lessons from the UK. Journal of Housing Economics 14, 178-193.

Shackleton, M.B., Wojakowski, R., 2007. Finite maturity caps and floors on continuous flows. Journal of Economic Dynamics and Control 31, 3843-3859.

Sheng, A., 1997. Housing finance and asian financial markets. Speech by the Deputy Chief Executive of the Hong Kong Monetary Authority delivered to the International Union for Housing Finance in Thailand on October 27, 1997.

Shiller, R.J., Weiss, A.N., 2000. Moral hazard in home equity conversion. Real Estate Economics 28, 1-31.

Smith, Jr., C.W., Warner, J.B., 1979. On financial contracting: An analysis of bond covenants. Journal of Financial Economics 7, 117-161.

Stanton, R., Wallace, N., 1998. Mortgage choice: What's the point? Real Estate Economics 26, 173-205.

Stiglitz, J.E., 1988. Money, credit, and business fluctuations. The Economic Record 64, 307-22.

Summers, L., 2008. America needs a way to stem foreclosures. Financial Times February 25, 11. 
Tables

\begin{tabular}{||c|c|c|c||}
\hline & $\begin{array}{c}\text { Shared Appreciation } \\
\theta_{H}\end{array}$ & $\begin{array}{c}\text { Contract rate } \\
i\end{array}$ & $\begin{array}{c}\text { Annual repayment } \\
i Q_{0}\end{array}$ \\
Standard mortgage: & $0 \%$ & $10.00 \%$ & $\$ 7000$ \\
& & & \\
$25 \%$ SAM & $25 \%$ & $9.35 \%$ & $\$ 6544$ \\
$50 \%$ SAM & $50 \%$ & $8.70 \%$ & $\$ 6088$ \\
\hline
\end{tabular}

Table 1: Simple Shared Appreciation Mortgage as a workout loan.

\begin{tabular}{|c|c|c|c|c|c|c|c|}
\hline & SAM & & & & ntract & & \\
\hline & & $\{\alpha=0$ & $\begin{array}{l}\left.T^{*}=0\right\} \\
\text { e } 0\end{array}$ & $\{\alpha=$ & $\begin{array}{l}\text { pe } 1 \\
\left.6 ; T^{*}=5\right\}\end{array}$ & $\{\alpha=$ & $\begin{array}{l}\text { pe } 2 \\
\left.o ; T^{*}=5\right\}\end{array}$ \\
\hline$\lambda$ & $\theta_{H}$ & $\begin{array}{c}i \\
{[\%]}\end{array}$ & $\begin{array}{l}i Q_{0} \\
{[\$]}\end{array}$ & $\begin{array}{c}i \\
{[\%]}\end{array}$ & $\begin{array}{l}i Q_{0} \\
{[\$]}\end{array}$ & $\begin{array}{c}i \\
{[\%]}\end{array}$ & $\begin{array}{l}i Q_{0} \\
{[\$]}\end{array}$ \\
\hline 0.03 & 0. & 10.00 & 7000.00 & 9.99 & 6989.76 & 9.93 & 6948.78 \\
\hline (50\% PSA) & 0.25 & 9.12 & 6384.69 & 9.11 & 6374.44 & 9.05 & 6333.47 \\
\hline & 0.5 & 8.24 & 5769.38 & 8.23 & 5759.13 & 8.17 & 5718.16 \\
\hline 0.06 & 0 . & 10.00 & 7000.00 & 9.97 & 6976.68 & 9.83 & 6883.40 \\
\hline (100\% PSA) & 0.25 & 8.95 & 6264.60 & 8.92 & 6241.28 & 8.78 & 6148.00 \\
\hline & 0.5 & 7.90 & 5529.20 & 7.87 & 5505.88 & 7.73 & 5412.60 \\
\hline 0.12 & 0. & 10.00 & 7000.00 & 9.92 & 6943.88 & 9.60 & 6719.42 \\
\hline (200\% PSA) & 0.25 & 8.72 & 6107.28 & 8.64 & 6051.16 & 8.32 & 5826.70 \\
\hline & 0.5 & 7.45 & 5214.55 & 7.37 & 5158.44 & 7.05 & 4933.98 \\
\hline 0.48 & 0. & 10.00 & 7000.00 & 9.55 & 6682.49 & 7.73 & 5412.44 \\
\hline (400\% PSA) & 0.25 & 8.35 & 5847.46 & 7.90 & 5529.95 & 6.09 & 4259.90 \\
\hline & 0.5 & 6.71 & 4694.93 & 6.25 & 4377.41 & 4.44 & 3107.36 \\
\hline
\end{tabular}

Table 2: Alternative contracts, including a $25 \%$ and a $50 \%$ SAM compared to a standard (0\% appreciation) contract. 


\section{Figures}

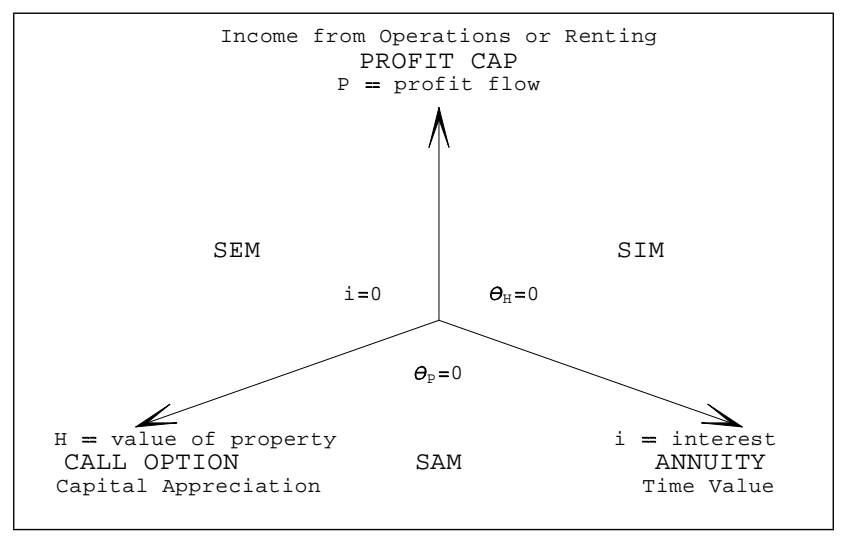

Figure 1: Participating mortgage loans. SIM stands for Shared Income Mortgage, SAM is Shared Appreciation Mortgage and SEM means Shared Equity Mortgage.

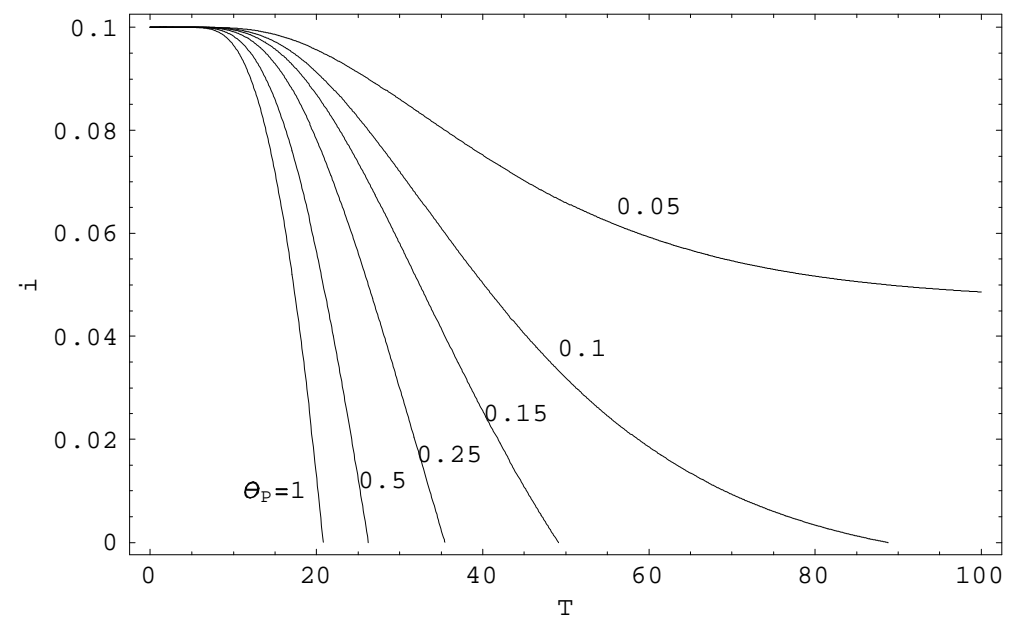

Figure 2: Dependence of the contractual interest rate $i$ on maturity $T$ of a Shared Income Mortgage (SIM). Parameters are $P_{0}=250000, K=1000000, r=0.1, \delta=0.05, \sigma=0.15$, $H_{0}=100000, \bar{L}=0.9$. Participation ratios are: $\theta_{P} \in\{1,0.5,0.25,0.15,0.1,0.05\}$. 


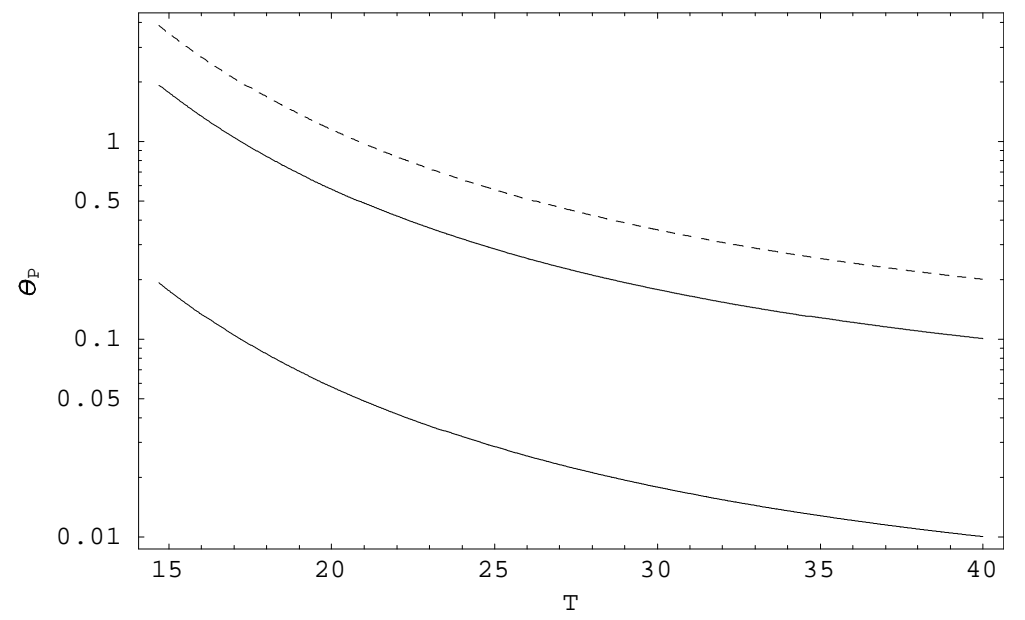

Figure 3: Dependence of the participation ratio $\theta_{P}$ on maturity $T$ for a Shared Income Mortgage (SIM). Parameters are $P_{0}=250000, K=1000000, r=0.1, \delta=0.05, \sigma=0.15$, $H_{0}=100000, \bar{L}=0.9$. Contractual interest rates are: $i \in\{0.095,0.05,0\}$. The dashed line represents the case $i=0$.

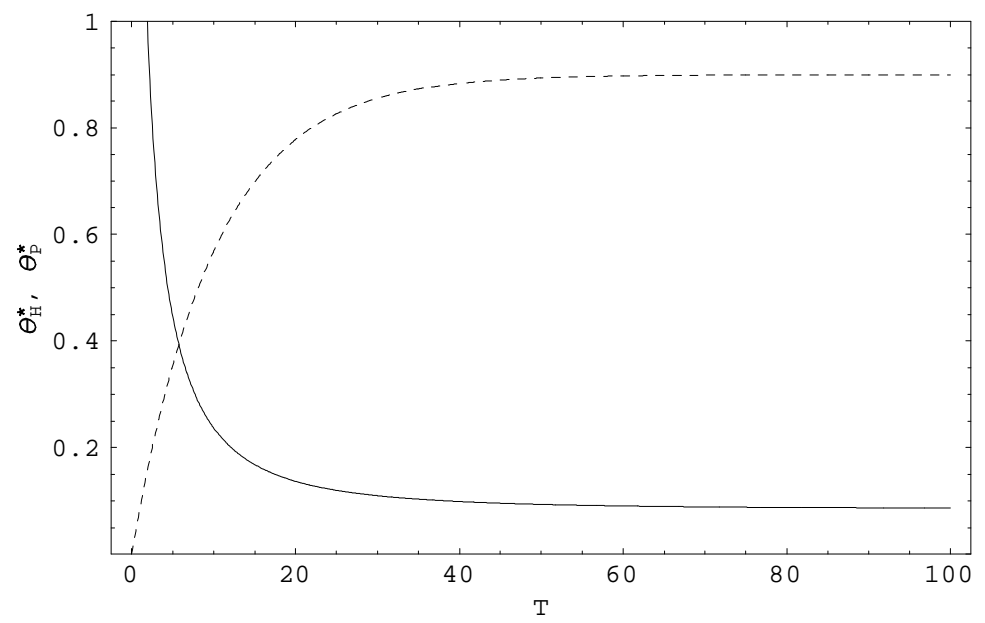

Figure 4: Real estate participation ratio $\theta_{H}^{*}$ (dashed line) and the profit participation ratio $\theta_{P}^{*}$ (solid line) for a Shared Equity Mortgage (SEM). Parameters $P_{0}=1000000, K=1000000$, $r=0.1, \delta=0.05, \sigma=0.15, \delta_{H}=0.05, \sigma_{H}=0.001, H=100000, \bar{L}=0.9$. 


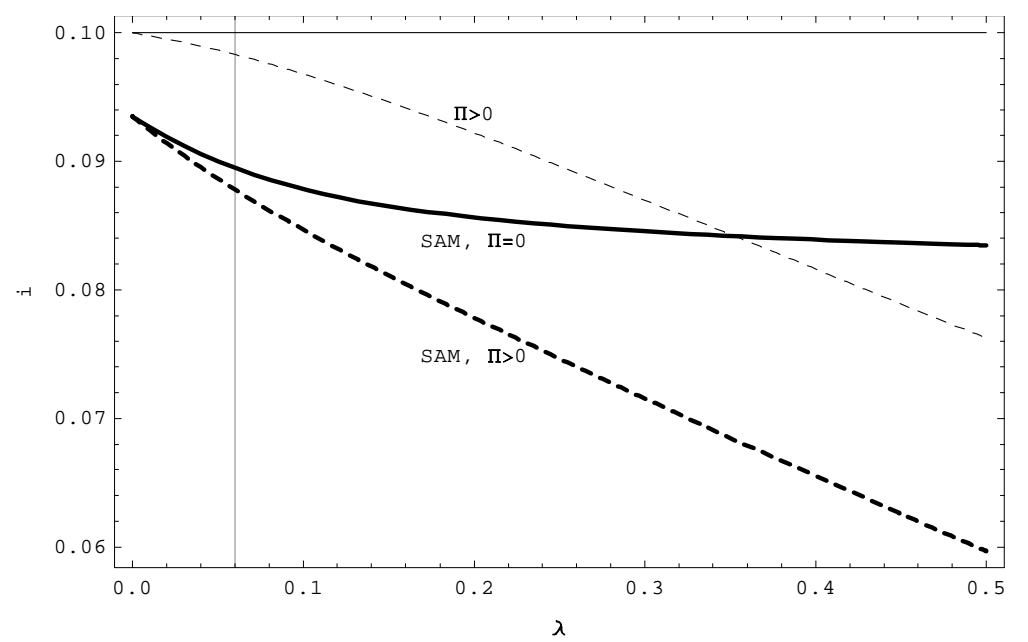

Figure 5: Dependence of mortgage rate $i$ on prepayment intensity $\lambda$ for a 25\% SAM as compared to a standard contract. Both standard and SAM contracts are considered with $(\Pi>0)$ and without $(\Pi=0)$ prepayment penalties. Thin flat line is the standard contract with contract rate fixed at $i=10 \%$ and without prepayment penalties $(\Pi=0)$. Thin dashed line is the standard contract with early prepayment penalty added $(\Pi>0)$. Thick line is a $25 \%$ SAM. Thick dashed line is a $25 \%$ SAM with early prepayment penalty added $(\Pi>0)$. In both cases the early prepayment penalty is defined by setting $\alpha=5 \%$ and applies for the first $T^{*}=5$ years. The reversal of contract rates occurs for high prepayment rates $\lambda$ for the SAM with no early prepayment penalty (SAM, $\Pi=0$ ) as compared to a high penalty standard contract with early prepayment penalties $(\Pi>0)$.

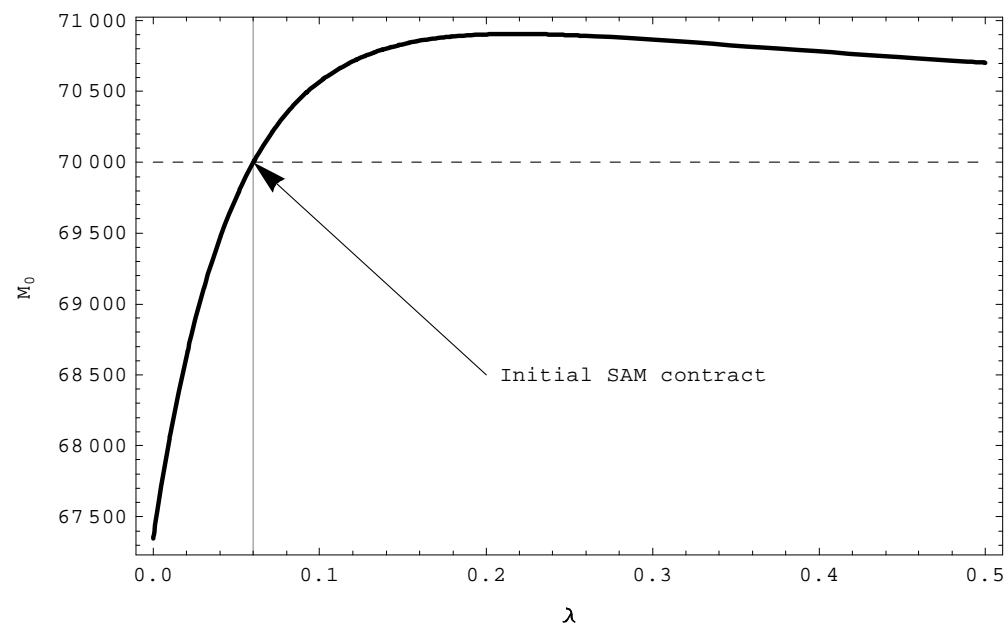

Figure 6: Dependence of mortgage value $M_{0}$ on prepayment intensity $\lambda$. Thick line is a $25 \%$ SAM without early prepayment penalty. 